\title{
Analytic Hierarchy Process based method to evaluate teacher's ability in network education
}

\author{
Junyan Zhao, Li Wang, YuLian Huang \\ Network Education College, East China University of Science and Technology, Shanghai 200237, \\ China \\ zhaojunyan@ecustmde.com, wangli@ecustmde.com, huangyulian@ecustmde.com
}

Keywords: analytic hierarchy process; teachers' ability; network education

\begin{abstract}
In network, teacher's ability is a key element to the teaching quality, and network education managers have to attach importance to teacher's ability evaluation. In this paper, we propose an analytic hierarchy process based method to evaluate the teacher ability, the social service, specific guidance, communication and cooperation, learning and innovation, and teamwork are considered in the evaluation process. On the basis of principles of teacher ability evaluation, analytic hierarchy process is used to evaluate teacher's ability, which can evaluate the teacher ability from different aspects, thus providing teachers with clear and actionable feedback to enhance their practice.
\end{abstract}

\section{Introduction}

Network education is a newly arisen education form with the advent of information age, which provides the possibility and reality of lifelong education for the whole people. The learners can use the Web to get network education anywhere and anytime, and Web-based network education plays a more and more important role [1, 2]. The basic feature can be summarized [3]: the providers and recipients of network education need get the network access permissions, the separation of teachers and students, the particular educational organization management the teaching process, the teaching content delivers through the computer network, the communication between teacher and student is two-way. With the development of computer technology, multimedia technology, communications technology, especially the rapid development of Internet has greatly promoted the development of network education. Network education is perceived by many instructors as innovation that has considerable potential for enhancing teaching and learning, promoting lifelong learning and reaching to non-traditional learners, about any degree type.

Network education is learner-centered system, the teacher can provide the course materials, such as curriculum plans, courseware and related information on the learning Website, the students can get those network courses and related services via computer and network [4]. In the learning process, the students can communicate with their teachers and students by using E-mail, discussion boards and chat rooms, the teachers can provide the guidance and help. The advantage of network education is: (1) The student can learn the related courses at any time and place. (2) It is more effective for some special learners, such as the distance learner, the learner with physical disabilities, learners have the talent in certain areas as well as those who love contemplative and good at writing to express their idea. (3) The teaching ways can be more personalized and flexible.

Network education has become a popular education mode. However, the teacher ability evaluation is a key aspect in network education and its strengths and weaknesses is a very important factor that affect the quality and the effect of network education. Now the network education supporting systems at home and abroad must meet their own characteristics [5]: 
(1) All teachers should be regularly evaluated by highly trained evaluators on the basis of clear standards as to what teachers should know and be able to do.

(2) Evaluations must be comprehensive, based on multiple indicators to provide teachers with clear and actionable feedback to enhance their practice.

(3) Evaluations must be meaningful, providing all teachers with clear and actionable feedback linked to tailored professional development.

(4) Evaluations must be fair, conducted by highly trained and objective supervisors or other evaluators as agreed to by the local affiliate, whose work is regularly reviewed to ensure the validity and reliability of evaluation results.

In order to satisfy these requirements, teacher ability evaluation systems must be adequately funded and staffed, and fully developed and validated. This paper proposes an analytic hierarchy process based method to evaluate teacher's ability. Below summarizes our main contributions: We propose four criterions, professional guidance, learning and creativity, social service, communication and cooperation to evaluate teacher ability from various aspects related to learning, and involve various objects associated with the learners. Then we use the analytic hierarchy process, which can evaluate the teacher ability from different aspects, thus providing teachers with clear and actionable feedback to enhance their practice.

The rest of this paper is organized as follows. Section 2 presents the related works, and Section 3 describes the criterions for teacher ability evaluation. Next, we give the analytic hierarchy process mechanism based method to evaluate teacher's ability. Finally, Section VII concludes.

\section{Related work}

Network education begins from the late of 1990's, only a small number of typical educational institutions can provide a small amount of online courses for the limited number of students. Now, more and more schools and institutions begin to offer online courses, and some institutions have begun to offer online certificate and degree.

Sloan-C is an online education institutions and organizations of Unite States, which is designed to promote the collaboration and sharing, thus improving the quality of online education knowledge and experience. From the results of Sloan-C, the scale and breadth of e-learning projects has already penetrated into all institutions of higher education [6], and has become the mainstream if higher education[7]. The overall proportion of network education as a long-term strategy is greatly rising [8]. Most of academic officials think that the effect of online education is as good as or better than traditional education [9].

Network education techniques are increasingly prevalent nowadays. The authors in Ref. [10, 11] have put forward an operation record and replay technique and implemented a tool, called SmartTutor, to create IDE-based interactive tutorials based on the technique. Remote desktop techniques, such as Virtual Network Computing in the Linux environment and screen sharing techniques [12], and the boom of consumer/client-centered culture in today's society leads to a trend of student-centered learning [13].

\section{Criterion for teacher ability evaluation in network education}

Teacher ability evaluation is not an independent existence, the evaluation may include the various aspects related to learning, and involve various objects associated with the learners. The existence and the goal of evaluation is to output the related teacher ability, and promote the development of teachers themselves. Teacher evaluation should be based on professional teaching standards and should be sophisticated enough to assess teaching quality across the continuum of development, from novice to expert teacher. Evaluations should include multifaceted criterion, such as teacher practice, student 
learning, and professional contributions that are considered in an integrated fashion, in relation to one another and to the teaching context. Any assessments used to make judgments about students' progress should be appropriate for the specific curriculum and students the teacher teaches. We will introduce the related criterions as follows.

\section{Professional Guidance}

The professional guidance is an important factor in network education. Network education emphasizes that the teaching content must adapt to the actual requirement, and the teaching content must be useful and professional. As for the teaching model, it emphasizes the integration of production, education and research, the teacher must fully understand and deeply analyze the teaching materials, curriculum software, etc. The teacher can answer and analyze the student's problems by using the professional knowledge.

\section{Learning and Creativity}

Network education has the "personalized" feature and high science and technology. In the teaching process of network education, teachers may face the "an individual learning object" or "a unique professional problem”, it not only relies on the traditional teaching means and methods, but also relies on the modern teaching means and media. Therefore, the teachers of network education must view the study as a regular teaching task.

\section{Social Service}

In network education, the service object of teacher is no longer the independent class, but the serving officers from the various social sectors. These changes require that the teachers of network education are not only the experts in teaching, but also the experts in industry. This means that the teacher of network education not only have a good teaching ability, but also has a certain skills about production practices. Therefore, the social service is an essential ability of teacher in network education.

\section{Communication and Cooperation}

In the network education, it separates the teachers and students, time and space, teaching and management, the communication and cooperation between them will become more important. How to use the network resources and modern means to impart knowledge to students, and how to use the scientific communication and network media to get the learning information of student, have become an important problem for the teachers in the network education. The master of communication and teamwork ability can supervise, inspect, guide and manage the network education.

\section{Analytic hierarchy process}

\section{Analytic Hierarchy Process}

The analytic hierarchy process (AHP) is a structured technique for organizing and analyzing complex decisions, based on mathematics and psychology. It was developed by Thomas L. Saaty in the 1970s and has been extensively studied and refined since then. AHP has been a tool at the hands of decision makers and researchers, and it is one of the most widely used multiple criteria decision-making tools [14]. The specialty of AHP is its flexibility to be integrated with different techniques like Linear Programming, Quality Function Deployment, Fuzzy Logic, etc. This enables the user to extract benefits from all the combined methods, and hence, achieve the desired goal in a better way.

Users of the AHP first decompose their decision problem into a hierarchy of more easily comprehended sub-problems, each of which can be analyzed independently. The elements of the hierarchy can relate to any aspect of the decision problem-tangible or intangible, carefully measured or roughly estimated, well or poorly understood-anything at all that applies to the decision at hand[15]. 
Once the hierarchy is built, the decision makers systematically evaluate its various elements by comparing them to one another two at a time, with respect to their impact on an element above them in the hierarchy. In making the comparisons, the decision makers can use concrete data about the elements, but they typically use their judgments about the elements' relative meaning and importance [16]. It is the essence of the AHP that human judgments, and not just the underlying information, can be used in performing the evaluations.

The AHP converts these evaluations to numerical values that can be processed and compared over the entire range of the problem. A numerical weight or priority is derived for each element of the hierarchy, allowing diverse and often incommensurable elements to be compared to one another in a rational and consistent way. This capability distinguishes the AHP from other decision making techniques.

In the final step of the process, numerical priorities are calculated for each of the decision alternatives. These numbers represent the alternatives' relative ability to achieve the decision goal, so they allow a straightforward consideration of the various courses of action.

\section{The Basic Steps of AHP}

The basic steps of AHP are:

Step 1: Establishing a hierarchical model. The model is generally divided into three layers, the top is the target layer, the bottom is the schema layer, and the intermediate layer is the rule hierarchy or index layer.

Step 2: Constructing the judgment matrix. It is accustomed to qualitatively distinct the object by using five attributes, that is, equally important, somewhat important, very strong, highly important, absolutely important, when the system need the higher accuracy, we can take a value between two adjacent properties, thus obtaining 9 values. In order to quantize the comparison and judgment, we introduce 1-9 to represent the different ratio. 1, 3, 5, 7, 9 are used to represent the judgments based on experience, the comparison between the element $i$ and the element $j$ : equally important, somewhat important, very strong, highly important, and absolutely important. 2, 4, 6, 8 are used to represent a compromise value between the two judgments.

Step 3. Computing the weight vector. The combined weight vector and do the consistency check.

Step 4. Computing the weight of basic elements. The following algorithm is used to literately compute the weight until e is a constant. The outputting e is the weighting matrix of elements.

The input and output of Algorithm is e, the initial value:

$\mathrm{e}=[1 / \mathrm{n}, 1 / \mathrm{n}, 1 / \mathrm{n}, \ldots 1 / \mathrm{n}], n$ is the number of elements.

- $\mathrm{e} 1=\mathrm{A} \times \mathrm{e}$;

- $\mathrm{a}=\operatorname{sum}(\mathrm{e} 1)$

- $\mathrm{e}=\mathrm{e} 1 / \mathrm{a}$;

- Go to Setp 1.

\section{Teacher Ability Evaluation}

The steps for evaluating teacher's ability are as follows.

Step 1: Creating a hierarchal structure. In the teacher evaluation system, it is usually divided into target layer (Overall rating of teacher), criteria layer, schema layer, the criteria layer mainly consider four factors, then compute the weight of each element in evaluating teacher ability based on the actual requirement. Finally, each element has its corresponding weight coefficient.

Criteria layer: it is mainly consider four aspects: professional guidance, learning construction ability, social service ability, communication and teamwork. The equations are an exception to the prescribed specifications of this template. You will need to determine whether or not your equation should be typed using either the Times New Roman or the Symbol font (please no other font). To create multileveled 
equations, it may be necessary to treat the equation as a graphic and insert it into the text after your paper is styled.

Schema layer: computing the weight coefficient $w_{1}, w_{2}, w_{3}, w_{4}$ of each element in criteria layer, then the overall rating of teacher is:

$$
\mathbf{Y}=\mathrm{w}_{1} \mathrm{X}_{1}+\mathrm{w}_{2} \mathrm{X}_{2}+\mathrm{w}_{3} \mathrm{X}_{3}+\mathrm{w}_{4} \mathrm{X}_{4}
$$

By computing Formula (1), we can get the overall rating.

We can express criteria layer by using the following figure:

\section{Step 2: constructing judgement matrix:}

$$
A=\left|\begin{array}{cccc}
1 & 3 & 5 & 1 \\
1 / 3 & 1 & 3 & 1 / 3 \\
1 / 5 & 1 / 3 & 1 & 1 / 5 \\
1 & 3 & 5 & 1
\end{array}\right|
$$

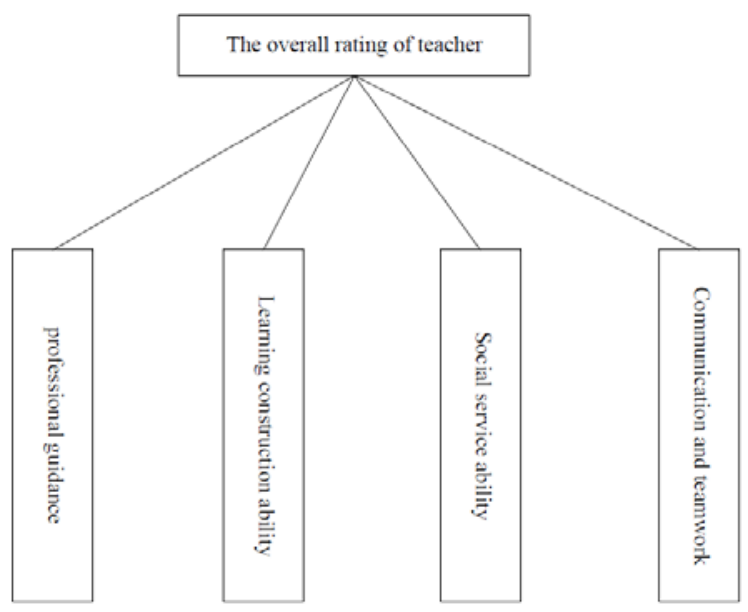

Figure 1. Criteria layer

Where 1 represents elements $i$ and $j$ are equally important, 3 represents element $i$ is slightly more important than $j$, while 5 represents that element $i$ is more important than $j$.

\section{Step 3: Consistency verification}

1) It is normalized to the following matrix based on the column: $\left|\begin{array}{cccc}15 / 38 & 9 / 22 & 5 / 14 & 15 / 39 \\ 5 / 38 & 3 / 22 & 3 / 14 & 5 / 38 \\ 3 / 38 & 1 / 22 & 1 / 14 & 3 / 38 \\ 15 / 38 & 9 / 22 & 5 / 14 & 15 / 38\end{array}\right|$

2) Computing the sum of each column, and normalizing to:

$$
W=\left(\begin{array}{llll}
0.389 & 0.153 & 0.069 & 0.389
\end{array}\right)^{\mathrm{T}}
$$

3). Computing the characteristic root:

$$
A W=\left|\begin{array}{cccc}
1 & 3 & 5 & 1 \\
1 / 3 & 1 & 3 & 1 / 3 \\
1 / 5 & 1 / 3 & 1 & 1 / 5 \\
1 & 3 & 5 & 1
\end{array}\right|(0.389 \quad 0.153 \quad 0.069 \quad 0.389)^{T} A W_{1}=1 * 0.389+3 * 0.153+5 * 0.069+1 * 0.389=1.582
$$

In the similar way, we can get: $A W_{2}=0.619, \mathrm{AW}_{3}=0.275, \mathrm{AW}_{4}=1.582$

4). Computing the max characteristic root: 


$$
\lambda_{\max }=\sum_{i=1}^{n} \frac{(\mathrm{AW})_{i}}{n W_{i}}=\frac{1.582}{4 * 0.389}+\frac{0.619}{4 * 0.153}+\frac{0.275}{4 * 0.069}+\frac{1.582}{4 * 0.389}=4.044
$$

5). Consistency verification:

$$
\text { C.I. }=\frac{\lambda_{\max }-\mathrm{n}}{\mathrm{n}-1}=\frac{4.044-4}{4-1}=0.015, \text { C.R. }=\frac{\text { C.I. }}{\text { R.I. }}=\frac{0.015}{0.89}=0.016
$$

We can get $\mathrm{CR}=0.0372<0.1$, so the inverse symmetric matrix can meet the consistency.

\section{Step 4: Computing the weight coefficient,}

1) $e=(0.25,0.25,0.25,0.25)$

$\mathrm{e} 1=(2.5,1.17,0.43,2.5)$

$\mathrm{a}=6.6$

$\mathrm{e}=(0.38,0.18,0.07,0.38)$

2) $e=(0.38,0.18,0.07,0.38)$

$\mathrm{e} 1=(1.65,0.64,0.29,1.65)$,

$\mathrm{a}=4.23$

$\mathrm{e}=(0.39,0.15,0.07,0.39)$

3) $e=(0.39,0.15,0.07,0.39)$

$\mathrm{e} 1=(1.58,0.62,0.276,1.58)$

$\mathrm{a}=4.06$

$\mathrm{e}=(0.39,0.15,0.07,0.39)$

The loop computation terminates, and the weight is $0.39,0.15,0.07,0.39$, that is, $\mathrm{w}_{1}=0.39, \mathrm{w}_{2}=$ $0.15, \mathrm{w}_{3}=0.07, \mathrm{w}_{4}=0.39$. The corresponding formula is:

$\mathrm{Y}=0.39 \mathrm{X}_{1}+0.15 \mathrm{X}_{2}+0.07 \mathrm{X}_{3}+0.39 \mathrm{X}_{4}$

\section{Conclusions}

In this paper, we proposed an analytic hierarchy process based method to evaluate teacher's ability in network education. This approach is based on AHP, which allows to take into account four criterions, professional guidance, learning and creativity, social service, communication and cooperation, in the evaluation process. AHP is used to evaluate the teacher ability, thus extracting benefits from all the combined criterions, and hence, achieve the desired goal in a better way. We can use this method to evaluate teacher ability, which has the merits of rich expressivity, while providing the teachers with clear and actionable feedback to enhance their practice

This paper has made progress in evaluating the teacher ability based Analytic Hierarchy Process. However, we do not consider other criterions. The reasoning mechanisms and tools are not covered. We will investigate these issues in future work.

\section{References}

[1] Y. Sun, D. Chen, W. Jiao, G. Huang, "An nnline education approach using Web operation record and replay techniques," Processing of the 38th Annual International Computers, Software and Applications Conference (COMPSAC 2014). Washington: IEEE Computer Society Press, 2014, pp.456465 
[2] Q. Li, R. W.H . Lau, B. Wah, et al, “Emerging Internet technologies for e-learning”, IEEE Internet Computing, vol.13, pp. 1-17, 2009

[3] Z. Hua, "The network education game design which based on the theory of Situated Cognition”, Processing of the 2nd International Conference on Computing, Control and Industrial Engineering (CCIE 2011). IEEE Computer Society, Washington, DC, USA, 2011, pp. 375-378.

[4] X. Yu, P. Li, X. Sun, "Researching on network education in institutions of higher learning”, The 2009 International Conference on Information Management, Innovation Management and Industrial Engineering. IEEE Computer Society, Washington, DC, USA, 2009, pp.466-469.

[5] New policy statement on teacher evaluation and accountability.http://www.nea.org/grants/46326.htm.

[6] The Sloan C. Entering the Mainstream: The quality and extent of online education in the United States, 2003 and 2004[EB]. http://WWW. sloanłC.org/publieations/survey/survey04.asp.

[7] The Sloan C. Growing by degreesOnline education in the United States, 2005[EB]. http://www.sloanłC.orgpublications/survey/ southern05.asp.

[8] C. Rodgers. Online eegrees haining acceptance, Enrollment[J]. Ełduexee. 2005(12): 4.

[9] A. Rea, D. White, R. McHaney, et a1, "Web-cased learning and teaching technologies: opportunities and challenges[M]”. Hershey,PA. USA:IGI Global Publishing, 2000, pp.135-154.

[10] Y. Zhang, G. Huang, N. Zhang, et al, "SmartTutor: Create IDE-based interactive yutorials via editable replay”, Proceedings of the 31st International Conference on Software Engineering (ICSE 2009), Formal Research Demo Track, 2009, pp. 559-562.

[11] N. Zhang, G. Huang, Y. Zhang, H. MEI, “Towards automated synthesis of executable eclipse tutorial”, Proceedings of the 22nd International Conference on Software Engineering and Knowledge Engineering, 2010, pp.591-598.

[12] T. Yamanoue, K. Shimozono, K. Oda, "Comparing a video projector and an Inter-PC screen broadcasting system in a computer laboratory”, Proceedings of the 38th annual ACM SIGUCCS conference on User services, 2010, pp.229-233.

[13] M. Gaeta, F. Orciuoli, S. Paolozzi, and S. Salerno, “Ontology extraction for knowledge reuse: The e-Learning perspective”, IEEE Transactions on Systems,Man, and CyberneticsłPart A: Systems and Humans, vol. 14, pp. 798-809, 2011.

[14] O. S. Vaidyaa, S.Kumar, “Analytic hierarchy process: An overview of applications, "European Journal of Operational Research, vol. 169, pp. 1-29, 2006.

[15] K. Osman. "Multi criteria decision making in product platform development and evaluation, "Proceedings of DESIGN 2010, 2010, pp.1623-1632.

[16] I. Basak,T. Saaty. "Group decision making using the analytic hierarchy process, "Mathematical and Computer Modelling. vol. 17, pp. 101-109, 1993. 